\title{
The role of managed healthcare in the South African context - A systemic approach
}

\author{
P.F. Hugo and S.S. Loubser* \\ University of Stellenbosch Business School \\ Stellenbosch 7600, Republic of South Africa \\ sloub@usb.sun.ac.za
}

Received August 2004

\begin{abstract}
Managed healthcare, in the context of this study, is defined as a series of management interventions in the healthcare supply chain, aimed at promoting appropriate and necessary care at a cost which is affordable to the consumer. It has evolved precisely because the healthcare supply chain is inefficient, too costly to be affordable to the majority of consumers in South Africa. Since managed healthcare represents a collection of interventions it is probable that these interventions will provoke responses which either support or counter the objectives of the intervening parties. The study focuses on trends which can be quantified in order to demonstrate this process, as well as on qualitative responses from role-players within the system, in order to explain behavioural changes that give rise to these trends.
\end{abstract}

\begin{abstract}
Managed healthcare is a management tool that is used in the private healthcare environment to manage the provision of care. In the past it was based on retrospective intervention and had cost containment as its main focus. Managed healthcare aims to address efficiency and quality of care but has yet to demonstrate measurable outcomes that would significantly impact on its WHO ratings. However, little attention is paid to the relationships and structure of the system within which care is provided and the dynamics that exist between and amongst role-players. The extent to which these relationships have an effect on the outcomes of the Private Healthcare Delivery System in South Africa is a relative unknown quantity. This article describes the research process which endeavours to develop a systemic approach to understand the current challenges in the PHDS better in order to optimise the outcome of it.
\end{abstract}

*To whom all correspondence should be addressed.

\section{Introduction}

The generally held view in the healthcare industry is that the most important problem in healthcare is the disproportionate escalation in costs. Most managed care organisations claim to focus on concurrent or prospective interventions in order to reduce the cost of healthcare in the private healthcare environment (Hoffman, 2004). Intervention programs vary in the balance between appropriateness of care on the one hand and cost and volume of care on the other.

Managed care programs should contain contribution inflation on the one hand and improve access to healthcare insurance on the other. Industry specific outcome measures should indicate better performance in terms of contribution cost to the consumer, accessibility by more consumers, efficiency of services rendered and quality of healthcare paid for by healthcare insurers. All indications are that these conditions are currently not being met.

This working paper creates the framework for a PhD study that will seek to analyse the South African Private Healthcare Delivery System (PHDS) and will highlight the unique characteristics, elements and variables as well as the dynamics of the PHDS. This will enable the role-players in the PHDS to meaningfully address the problems experienced. The study aims to introduce the use of systems thinking and systems theories into the PHDS and, with the use of the Delphi technique, identify the unique characteristics, systems dynamics and elements to be incorporated into an ideal management system.

\section{Problem statement}

The delivery of healthcare services by healthcare professionals within a third-party funded system is subject to a number of variables and complexities which result in sub-optimal outcomes from both an industry and patient perspective. Managed Healthcare attempts to address these complexities and variables in order to produce more appropriate outcomes. An inherent weakness from a economic point-of-view is the absence of normal supply and demand dynamics, lack of co-ordination of the services provided and mal-alignment of the objectives of the major role-players in the industry.

\section{Background}

According to a study by the World Health Organisation (WHO), South Africa was rated 175th for overall performance of its health system, out of 191 countries surveyed. South Africa ranked $57^{\text {th }}$ in terms of the amount of money spent on health, but was $182^{\text {nd }}$ when it came to the effectiveness of healthcare spending. South Africa ranked 
$142^{\text {nd }}$ when it came to the fairness with which healthcare resources are distributed (Sunday Times, 18/6/2000).

Overall performance is rated as the performance of the health system as a whole, given the resources available. Analysis of the data from the World Health Organisation (2000) reveals that South Africa is clustered with Niger, Equatorial Guinea, Rwanda, Afghanistan, Cambodia, Guinea-Bissau, Swaziland, Chad, Somalia and Ethiopia in the overall health system performance range 170-180. South Africa ranked best in this group in terms of US\$ matched healthcare expenditure per capita, but third from the bottom, just ahead of Niger and Cambodia, in terms of fairness in distribution of financial expenditure (WHO, 2000).

These ten countries' ranking by performance in terms of level of health in the population equated largely with their overall rankings. If one looks at the US\$ expenditure per capita of the countries in the cluster, only Swaziland approached South Africa in the quantum spent on healthcare. In all other cases South Africa spent between 5 and 40 times more than its cluster counterparts.

Looking at expenditure per capita South Africa is clustered with Panama, Brazil, Mexico, Croatia, Poland, Hungary, Estonia, Cook Islands and Oman. With the exception of Brazil (111), all South Africa's counterparts managed rankings below 80 in terms of Health Level (measured in terms of disability adjusted life years overall life expectancy). Seven managed better ratings than South Africa in terms of responsiveness to population expectations, five managed better ratings in terms of fairness in financial contribution and all managed better ratings in terms of overall goal attainment.

It is thus evident that South Africa is getting less value for its healthcare Rands spent compared with its counterparts and that performance is less efficient than that of most of its cluster counterparts, and obviously also less efficient than the rest of the countries listed.

Another reason for South Africa's poor performance is that funding for healthcare in the private and public sectors differs significantly in the total amount available per beneficiary served. Current health care expenditure in the private sector amounts to $\mathrm{R} 5112.80^{1}$ per beneficiary (Council of Medical Schemes, 2003), whereas in the public sector the figure is much lower, about R1100,00² per individual for the same period. This would account in part for the low ranking in terms of fairness (refer Figure 1).

The private versus public healthcare spending ratio is illustrated in Figure 1.

Current healthcare spending amounts to around $11 \%$ of total government expenditure and is projected to increase by 2,8\% per year (Department of Finance, 2004). Taking these budget constraints and South Africa's socio-political

${ }^{1}$ R35,6Bn / 6962914 members (CMS Report 2002/3).

${ }^{2} \mathrm{R} 39,7 \mathrm{Bn} / 36$ million (Budget Highlights - Department of Finance, 2004) situation into account, it is evident that the public health system will not be able to solve the problems experienced in the public and / or private sectors.

Within the private healthcare environment, about $16 \%$ of the population have access to private healthcare through medical insurance and another small percentage pays cash for services rendered by the private healthcare fraternity (Council of Medical Schemes, 2003). Medical inflation exceeds the CPI year after year. Overall increases in real terms were 351\% over 15 Years (Hartley, 2001). Thus, the average annual increase was $23,4 \%$.

\section{The traditional role of managed healthcare (MHC)}

Managed healthcare is a management tool that is used in the private healthcare environment to manage the provision of care. In the past it was based on retrospective intervention and had cost containment as its main focus. Greater focus is now placed on concurrent and prospective intervention. MHC aims to address efficiency and quality of care, but has yet to demonstrate measurable outcomes that would significantly impact on South Africa's WHO rating (Hoffman, 2004). However, little attention is paid to the relationships and structure of the system within which care is provided and the dynamics that exist between and amongst role-players.

When the needs of the role-players (refer Figure 2) are analysed, it is ironic ${ }^{3}$ that what appear to be the legitimate needs of the different role-players all result in higher costs and/or negatively influence accessibility, quality and efficiency of care. Perceived legitimate needs, which would be acceptable in most other economic or commercial systems, may contribute to unacceptable cost and/or accessibility, efficiency and quality outcomes. In order to address this fundamental concern, it will be necessary to separate needs realisation from each role-player's ability to manipulate the system in order to attain either legitimate but unaffordable or inappropriate needs.

Patients' legitimate needs are the resolution of a physical or emotional disturbance or illness. In order to fulfil this need, a patient requires the perceived 'best' services available in whatever quantity it takes to resolve the physical or emotional disturbance or illness. No clear benchmark exists by which the application of healthcare services (type or quantity) can be compared. The fulfilment of a patient's needs can therefore adversely affect costs, access, quality and efficiency within the PHDS.

\footnotetext{
${ }^{3}$ Ironic in the sense that as people live a healthier life, the number of consults and prescriptions should decrease, advanced technology should mean less consultations, and better IT systems should lessen the administration burden, etc.
} 


\section{Private versus Public sector resources}

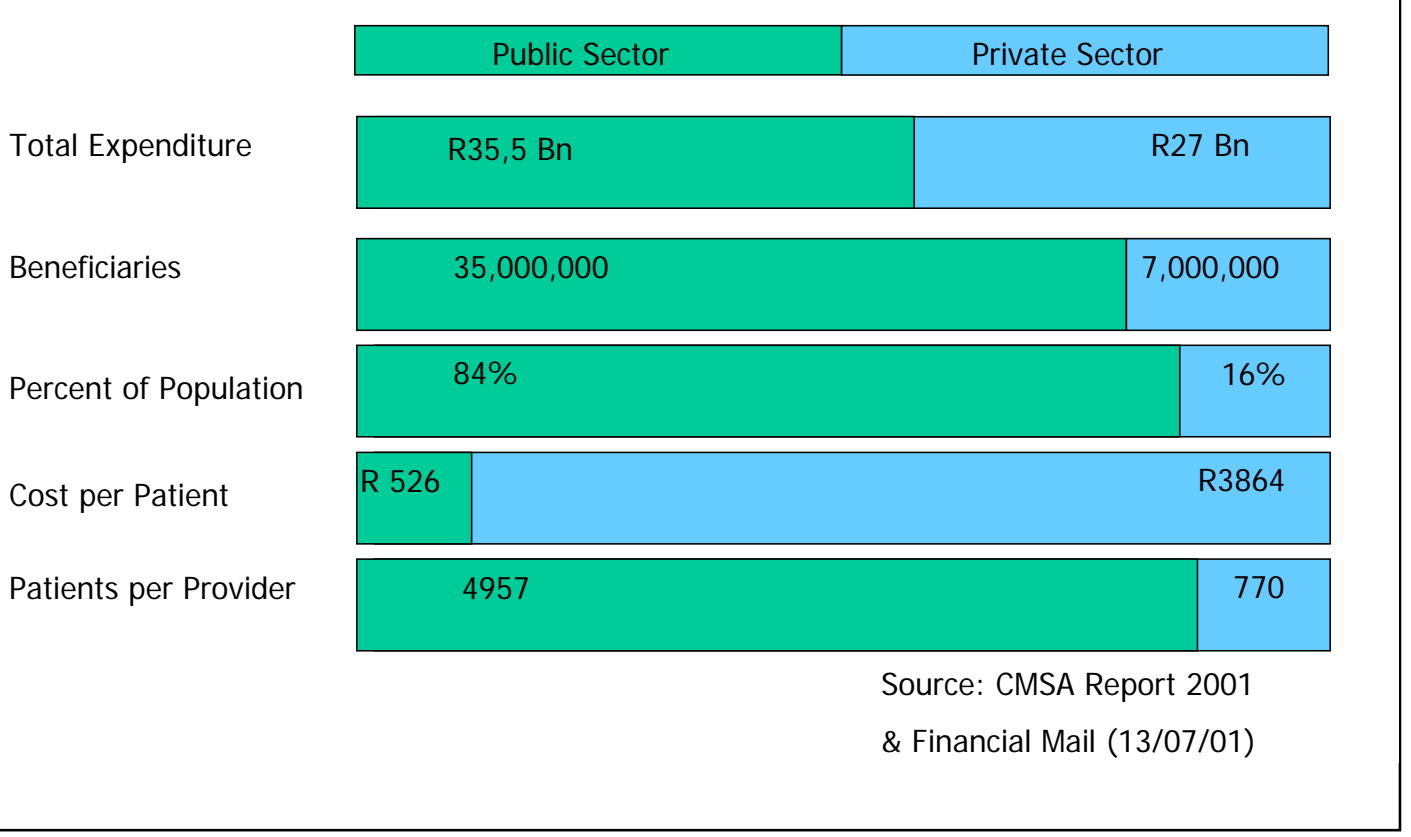

Figure 1: Public versus private sector spending

\begin{tabular}{l|l|l}
\hline Stakeholder & Need & Criteria for measurement of success \\
\hline Patient & $\begin{array}{l}\text { Resolution of a physiological or emotional } \\
\text { disturbance }\end{array}$ & $\begin{array}{l}\text { Return to a state of “complete physical, } \\
\text { mental, and social well-being” }\end{array}$ \\
\hline Healthcare Providers & Both professional and financial success & Adequate professional income \\
\hline Medical Scheme & Membership and solvency & $\begin{array}{l}\text { Member retention and development of } \\
\text { adequate financial reserves }\end{array}$ \\
\hline Medical Scheme Administrator & $\begin{array}{l}\text { Profit and adequate performance of } \\
\text { administrative functions }\end{array}$ & $\begin{array}{l}\text { Efficiency in transaction processing and } \\
\text { retention of Medical Scheme clients }\end{array}$ \\
\hline
\end{tabular}

Figure 2. Role player needs analysis.

Healthcare providers' legitimate needs centre largely around professional and financial success. They would like to be sure of adequate income within an environment conducive to the fulfilment of this need. Because these needs are open-ended and realisation depends on the quantity and type of service provided, irrespective of appropriateness, these needs can adversely affect costs, access, quality and efficiency within the PHDS.

The needs of the Schemes centre around continued viability and growth as well as compliance with legislative requirements. If these requirements are set unrealistically by the regulator, these needs will adversely affect costs, access, quality and efficiency within the PHDS. Schemes have a limited set of options for realising needs driven by the regulatory environment. They focus mainly on increasing contribution cost and/or reducing type and quantum of benefits available. Without the assistance of programs which reduce the overall risk to the scheme, schemes may not be able to comply with regulatory requirements and grow membership without impacting negatively on the outcomes measure listed above.
Administrators' primary needs are that of making an acceptable and sustainable profit in order to satisfy their shareholders. Their secondary need is to adequately perform the tasks of administering claims. The extent to which the administrator can fulfil its operational responsibilities with improved efficiency and with increasing degrees of sophistication will impact significantly on outcome measures. In the absence of improved productivity, operational efficiency and management sophistication, the administrators' legitimate need to make a profit may result in significant additional cost to the scheme, impacting secondarily on access, quality and efficiency within the PHDS.

It is clear that:

- $\quad$ role-players do not have the same needs;

- role-player behaviour is focused on the fulfilment of individual role-player needs; 
- none of the needs driving role-player behaviour have the survival of the system as a whole in mind, certainly not primarily or directly;

- $\quad$ the effect of inappropriate role-player behaviour results not only in higher costs, but limits access to private healthcare services, creates a delivery system that is almost impossible to co-ordinate effectively, creates a supply and demand imbalance and results in reduced quality of care; and

- as most of the needs are at least perceived to be legitimate, they cannot simply be dismissed, but require sensitive and constructive management in order to achieve the highest level of appropriate efficient care within the financial constraints of the funds available.

A graphic illustration of role-player needs is provided in Figure 3.

Within a complex environment like that of the Private Healthcare environment, it is necessary to establish a new order that:
- will ensure the survival of the PHDS as a whole;

- is able to answer to the realistic and legitimate needs of the different role-players;

- addresses the most relevant outcomes of the healthcare environment; and

- is of benefit for all South Africans.

The focus of managed healthcare should be to work towards creating an environment within which the above-mentioned issues can be addressed. This may involve a more complex management strategy than the traditional cost management approach.

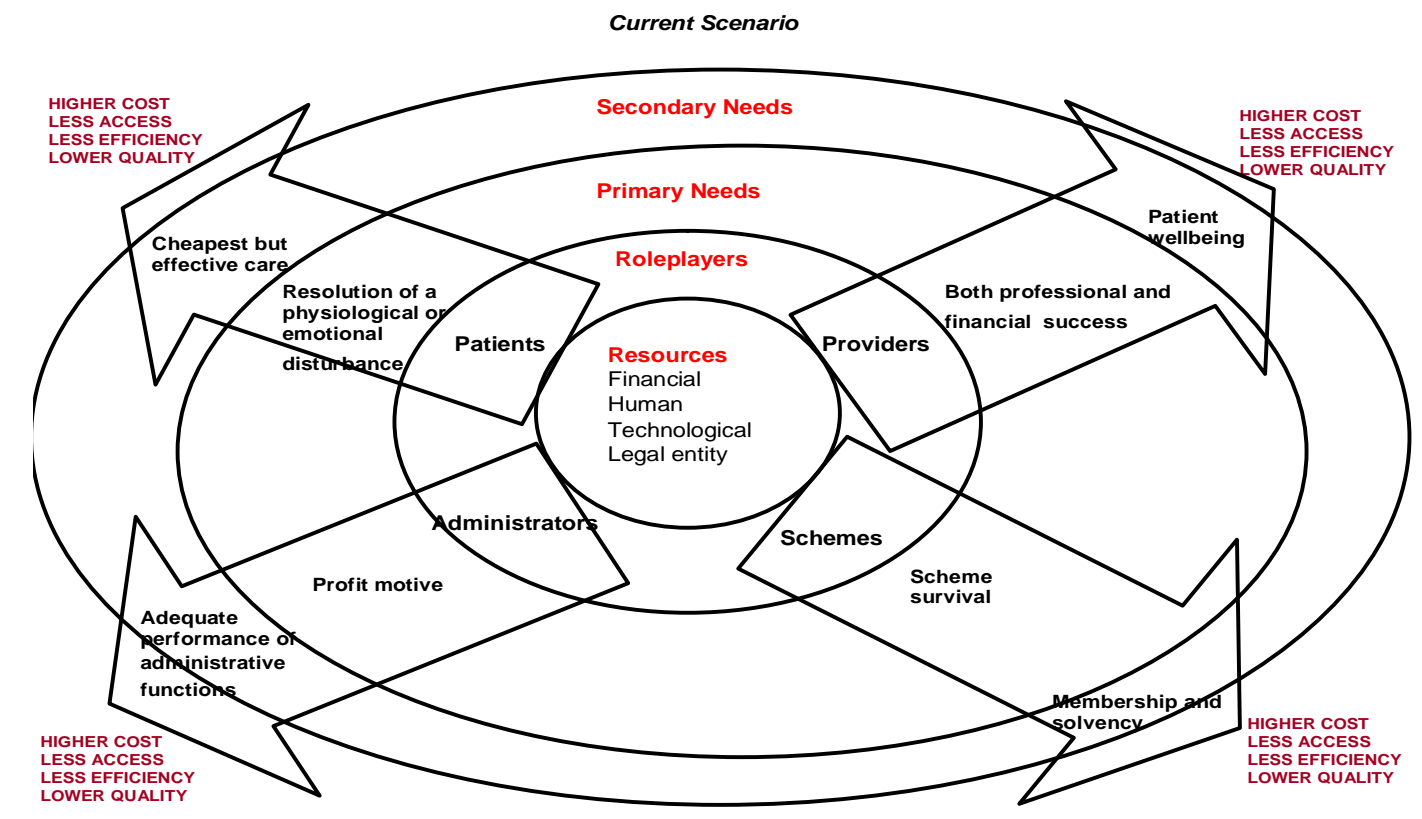

Figure 3: Resources, role-players and needs - the current scenario

\section{Research Methodology}

The research roadmap of the study includes a systems analysis of the PHDS (refer Figure 4). The PHDS will be analysed with the use of frameworks developed by Ackoff, (1974) Gharadejaghi, (1999) and Senge, (1994). Quantitive analysis of medical scheme data will indicate the success/failure of the current managed care interventions by analysing the intervention/response cycles. The Delphi Process will consist of 3 phases where a panel of experts will be used to assist in the development of an alternative managed care model.

\section{System analysis}

The healthcare environment is seen as a learning organisation, which is defined by Drucker (in van Wyk, 1996) as the organisational concept of the future; 'a learning organisation in fact is one that continually expands its capacity to create its own future. Systems theory helps us sense as well as appreciate our connection to a wider whole. We can only meaningfully understand ourselves by contemplating the whole of which we are an integral part. Systemic thinking is the discipline which highlights the interrelationship of role-player actions with a system rather than focusing on these actions as isolated events.

System thinking brings a new dimension to the process of understanding the PHDS. Whereas managed healthcare has 
attempted to understand and influence the PHDS in a component based fashion, systems thinking looks at the PHDS from a holistic point of view and identifies the interrelationship of role-player behaviour. The systems framework used in this study for purposes of analysis draws mainly on the work of three systems thinkers.

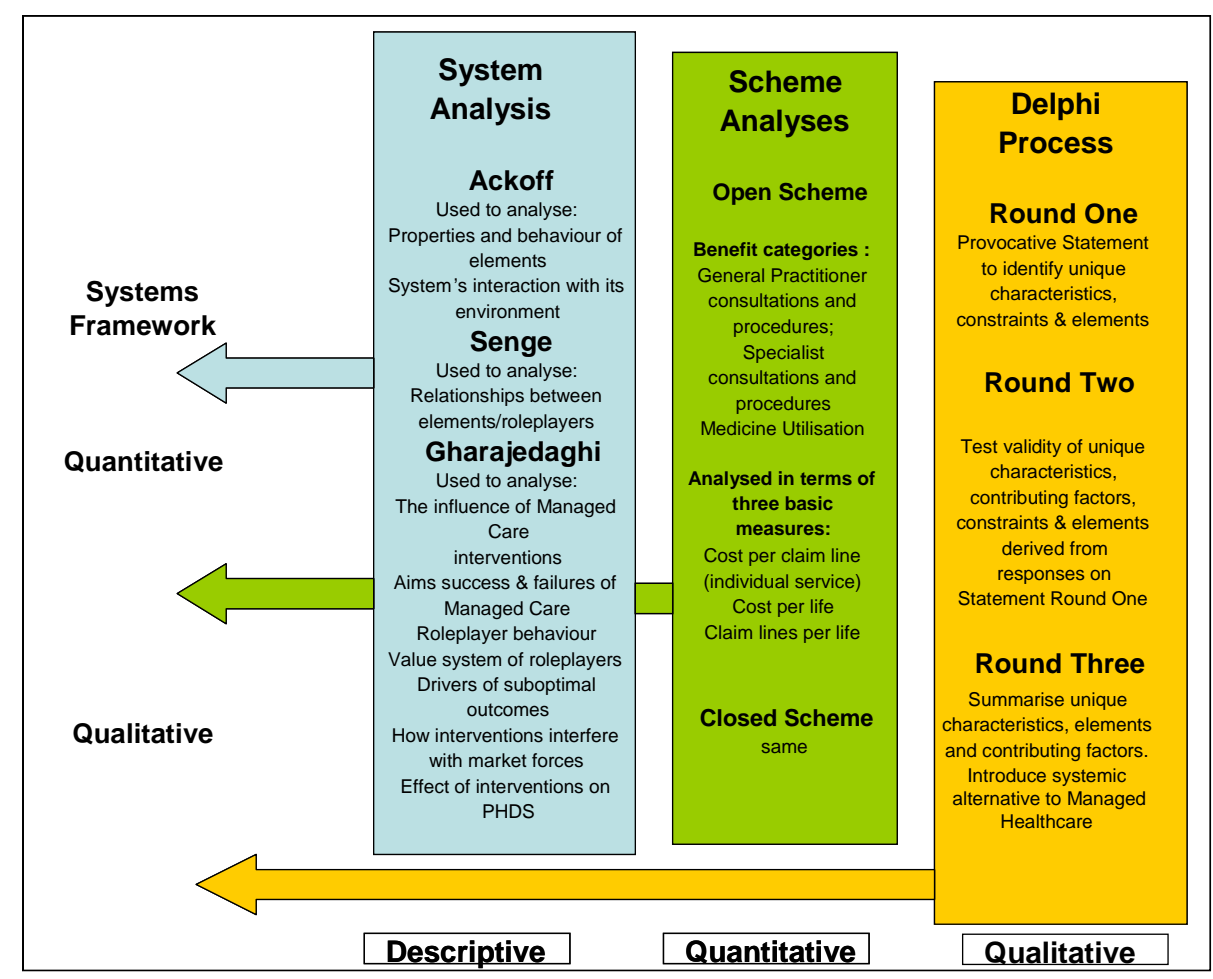

Figure 4: Research roadmap

Drawing on the work of systems theory experts such as Ackoff and Gharajedaghi (from the ideal design school) and Senge (from the systems dynamics perspective), this study aims to:

- Identify the major dynamics that determine or influence the outcomes in respect of cost, access, quality and efficiency of healthcare delivery by the PHDS.

- Identify critical systemic flaws that undermine management attempts to create optimal outcomes.

- Propose a systems based alternative managed care strategy that will aim to improve the probability that given management interventions will result in improved outcomes.

Within this research process, conventional systems methodologies were used to analyse the current state of the PHDS. These methodologies allowed the researcher to analyse the PHDS from a current systems logic point of view - a process that has not been done on this level and which is a worthwhile exercise and it allows for an in-depth understanding of the PHDS from a systemic perspective. The use of the conventional theories of Ackoff, Gharadejedaghi and Senge allowed the researcher to identify the elements, variables and unique characteristics of the PHDS as well as the dynamics that drive the system - each of which will have to be incorporated into an alternative managed healthcare methodology. This research will with the use of the Delphi technique identify the unique characteristics, elements and variables within the PHDS that have an influence on managed healthcare as well as introduce a systems based alternative for managed healthcare.

Ackoff's (1974) description of the properties and behaviour of elements as well as the system's interaction with its environment are used in the analysis of the PHDS and to assist in the development of a model depicting the PHDS from a systems point of view. Ackoff highlights the characteristics that a management system must have if the managed system is to learn and adapt effectively.

Gharajedaghi's (1999) is of opinion that while natural sciences have discovered 'chaos', and social science encountered 'complexity', 'chaos' and complexity are not inherent characteristics of our current reality, but simply features of our perceptions and understanding. Gharajedaghi’s systems principles are used to:

- $\quad$ describe the influence of managed care interventions;

- describe the aims, successes and failures of managed care interventions;

- $\quad$ analyse role-player behaviour;

- $\quad$ understand the value system of role-players; 
- understand the drivers of sub-optimal systems outcomes;

- understand how management interventions interfere with normal market forces; and

- $\quad$ understand the adverse effect of current management interventions on the PHDS.

Senge (1994) argues that we are taught from an early age to make complexity apparently more manageable by breaking wholes into parts. This makes understanding wholes pretty much impossible since we can no longer appreciate results of action because the whole is stripped on an essential quality -interrelatedness.

Senge’s (1994) systems archetypes are used to:

- $\quad$ catalogue behaviour of role-players;
- $\quad$ analyse the behaviour of the different role-players toward the system (primary level); and

- $\quad$ towards each other (secondary level).

These concepts of systems theory used in this study will create an understanding of the PHDS as a complex social system and to extract structural and management principles that will ultimately improve the functioning of the PHDS.

\section{Quantitative analysis}

The study will focus in its quantitative research section on the utilisation data of a number of different schemes that are representative of the healthcare industry and will be analysed in order to depict trend lines as shown in Figure 5. This will illustrate a quantitative depiction of behaviour change by role-players over time and assess the impact of that change on the PHDS as a whole.

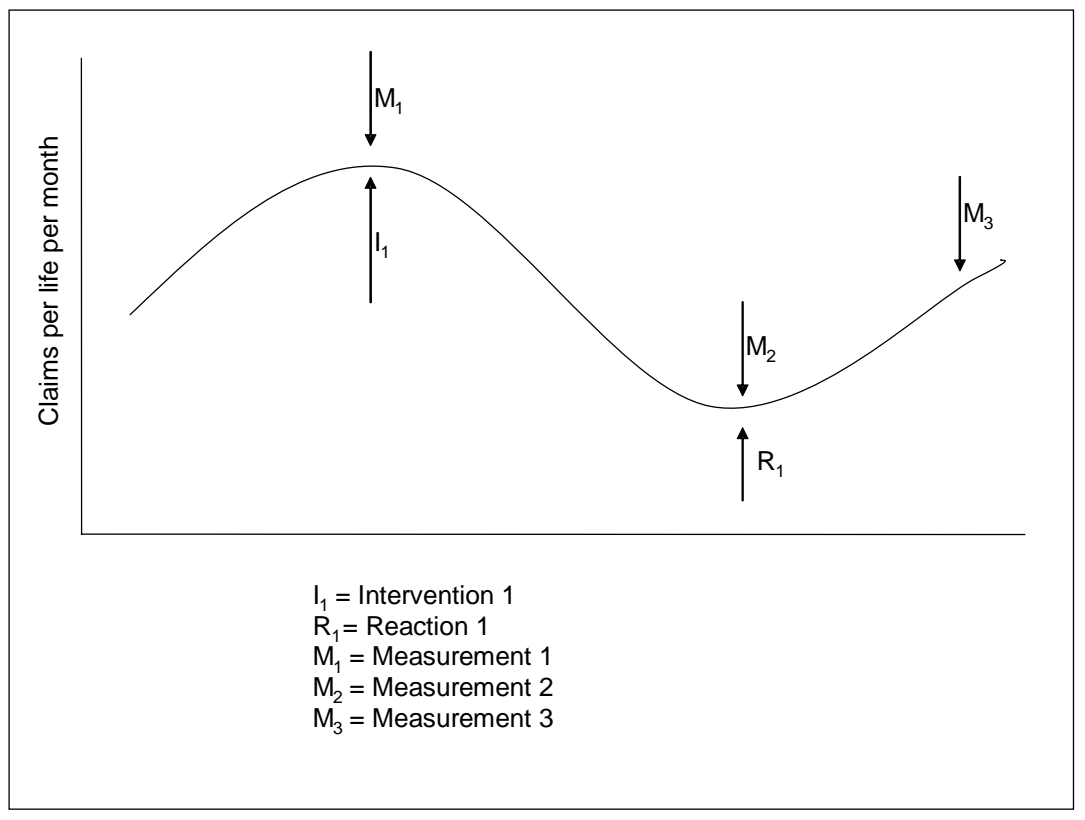

Figure 5: Claims per life per month utilisation curve of medical schemes

In general terms, Figure 5 depicts an expected interventionresponse pattern. The measurement parameter, claims per life per month, shows a positive year-on-year percentage change until $I_{I}$, when there is a rather abrupt decrease in the year-on-year percentage change in the measurement parameter. This is followed at a future point $R_{I}$ when there is once again an increase in the year-on-year percentage change in the measurement parameter. This pattern may repeat in a cyclical fashion as the system is subjected to managed care interventions by the administrator and responses from providers and/or patients.

$\mathrm{M}_{1}$ represents a point on the trend line that constitutes a certain profile of services supplied by the providers to beneficiaries belonging to the scheme. $I_{1}$ represents an intervention in the form of a managed care initiative and this has the effect of a declining trend line. $M_{2}$ represents a turning point when the profile of services supplied by providers once again increases. At point $R_{1}$ some change in behaviour, or a reaction, results in another positive year-onyear percentage change in the measurement parameter - the trend line accordingly demonstrates an upward curve that leads to M3, which represents yet another profile of services. This is a typical systems characteristic where the system returns to its original state.

The primary purpose of the quantitative analysis in the study is to evaluate whether managed care interventions provide long-term desired responses to the problem of excessive uncontrolled utilisation of services and, if possible, to predict what responses those interventions may evoke.

The study further aims to use quantitative analysis to analyse the reasons behind the upswing of the trend line between $\mathrm{M}_{2}$ and $\mathrm{M}_{3}$ and to identify the extent to which this is driven by role-player behaviour. This will identify both 
the areas in which managed care should focus its efforts, as well as the probable impact of those efforts, with the objective of suggesting interventions which are more likely to promote negative change or counter positive change in the measurement parameter, in order to eliminate the effects of the upward trend line as shown above.

\section{Qualitative analysis}

The study will use qualitative analysis to research role player perceptions in order to estimate the degree and nature of behavioural change which was triggered by the managed care intervention. These perceptions about the impact of given historical interventions may provide a basis for testing future interventions and identifying those interventions which are likely to have a more sustainable impact.

The study will use the Delphi technique, which is a consensus method of research to develop management principles that will satisfy the needs of the different roleplayers as well as those of the private healthcare system as a whole. A panel of experts from each of the different roleplayers will be handpicked and they will complete interactive surveys. This process will eliminate potential bias due to individual group dynamics, allows participants to operate free from peer pressure and allow them time for reflection where opinions can be reviewed.

The research will analyse the interrelationships between role-players and the impact that these relationships have on the PHDS, on role-player behaviour, and the impact that these role-players and relationships have on MHC. The attitudes and perceptions towards MHC as well as the strategies in dealing with MHC will be analysed.

The information required from role-players will include the following:

- $\quad$ The nature of healthcare as a commodity.

- $\quad$ The role of the third-party funder.

- $\quad$ The attitude of role-players towards MHC.

- $\quad$ The role-player's perception of the role of MHC.

- $\quad$ The role-player's perception of the feasibility of MHC.

- $\quad$ The role-player's perception of the impact of MHC.

- The role-player's perception of MHC as a mechanism to:

o control both contribution and healthcare service costs,

o increase access to services,

o increase efficiency of delivering care, and

o increase quality of care delivered.

- $\quad$ The role-player's perception of whether MHC is aimed at changing behaviour.
- The role-player's perception of whether MHC has the ability to change behaviour.

- The role-player's perception of the driving forces that change behaviour.

- Whether MHC influences decision-making.

- Whether MHC interferes with clinically appropriate decision making.

- The role-player's ability to side-step MHC interventions.

- Whether role-players purposefully change behaviour to side-step MHC interventions.

- Whether MHC in its current format is a sustainable overall solution.

\section{A new role for managed healthcare}

The recently proposed legislation of the National Health Bill may, if implemented, change the playing field dramatically. Role players in the private healthcare arena need to realise that, if the solution does not come from within the private healthcare fraternity, the Government may pursue a social health system, which will have far-reaching implications for the PHDS. In the event that the new proposed system fails, an alternative should be available, i.e. a model developed by the role-players for the benefit of all.

Current government policy with regards to the proposed Certificate of Need (Sections 36-41 of the new National Health Act, Act 61 of 2003) attempts to regulate the needs of providers to provide services in the wealthier, over-traded areas, rather than where the accessibility needs of the consumers are greatest - in the rural areas. In every aspect of healthcare delivery, the supply chains are bloated with excessive cost and unnecessary utilisation, driven by unrealistic consumer demand and the needs of providers to ensure a specific level of income. Providers survive in areas where the patient to provider density is higher, not by competing with one another but by driving greater utilisation out of a smaller patient base (Schickeling, 2002). One aspect of the State's strategy to redistribute resources is the introduction of a Certificate of Need without which any new healthcare facility or provider may not operate in a given area.

Figure 6 represents an ideal scenario. Research has shown that the current scenario (as per Figure 3) has outcomes of high costs, inadequate access, low levels of efficiency and a certain level of quality (Beeld, 19/3/2003). ('Fokus op koste laat gehalte in slag bly'); Business Day, 14/1/2003. 'Staying alive in SA is a costly business'; Business Day, 14/3/2001. "Private health care is 'massively wasteful'). In order for the private healthcare delivery system to answer to those needs, a radical redesign of the current scenario is necessary. Figure 6 is this researcher's proposed typology of the ideal situation. 


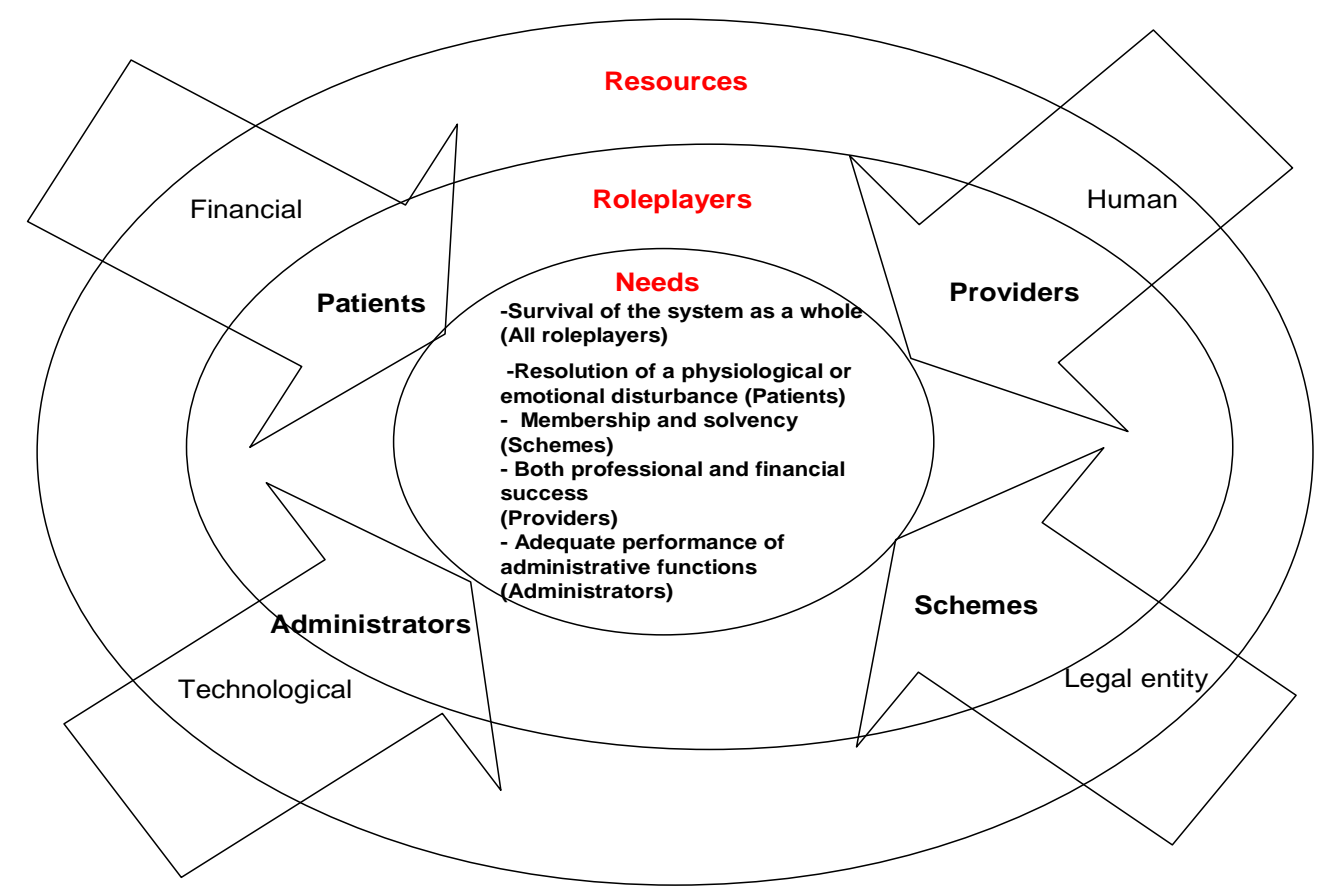

Figure 6: Resources, role-players and needs - the ideal scenario

The outcomes of the PHDS, namely cost, access, quality and efficiency of care, is to a great extent driven by the needs of the different role-players. Within an ideal healthcare scenario the needs of the role-players (the inner most circle) should be to acknowledge the fact that in order for one to thrive, all role-players should thrive. Thus, one should recognise the need for the PHDS system as a whole to thrive, then also acknowledge each individual role player's needs, while acknowledging the fact that all role players' needs must be satisfied to some extent in order for the system to thrive. If this can be achieved, it is theoretically possible to get the role players to work towards a common goal rather than towards their own individual goals.

\section{The purpose of an improved system.}

Between the current and ideal scenario an alternative management model needs to be constructed that will facilitate this change.

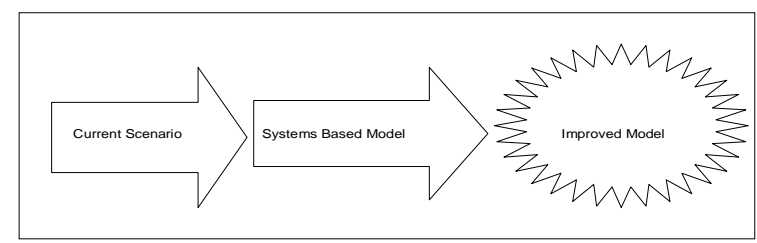

Figure 7: The role of the systems based model

For reasons mentioned earlier, the design of an ideal system falls outside of the scope of this research and this article, but the major dynamics, elements, variables and unique characteristics are identified and alternative managed healthcare strategies will be presented.

The use of systems theory and thinking promotes the idea that the whole is bigger than the sum of the parts. In other words, the whole private healthcare delivery system is bigger than the sum of the parts made up of the individual role players. Role players should understand that they are only one element of a bigger system. They should also understand that their behaviour has an effect on the well being of the system as a whole and that the current system is not producing desired outcomes.

If possible, the ideal would be to get the role players to agree that the most important aspect is a) for the current private healthcare delivery system as a whole to survive and b) that none of the role-players are dispensable. Thus, top priority for all role players should be to ensure the survival of the system and, secondly, the individual needs should be catered for, not in an individual manner, but as a whole.

Events within a system appear to be distinct in space and time, but they are all interconnected. Events, then, can be understood only by contemplating the whole. Life events can be better understood only in the knowledge that our actions contribute to patterns of interrelated actions. The world is whole and the whole is complex (Senge 1994). The PHDS is also a complex environment in which there are four major role players. Those role players act and interact on a continuous basis. Role players are also influenced by variables over which they have no control. Role players are dependent and interdependent on each other. Actions of one role player can have an effect on one or more role players as well as on the PHDS as a whole. The system gets 
increasingly complex with more and more information and actions, interdependencies and changes that take place. The system's purpose is that of providing healthcare, while its dynamics and information flow are created by role-players interacting on a continuous base.

The trouble is, Senge (1994) argues, that we are taught from an early age to make complexity apparently more manageable by breaking wholes into parts. This makes understanding wholes pretty much impossible since we can no longer appreciate results of actions because the whole is stripped of an essential quality - interrelationship. Similarly, if we think of ourselves as a disconnected part, we lose sense of our connection to a wider whole and inadvertently alienate and disempower ourselves. We are disempowered because we cannot grasp why events happen in our lives in the way that they do. In the same sense, the different role players in the private healthcare arena are interconnected; if, for example, providers behave in a way that will benefit them, it might be of a disadvantage to another role player or all role-players, or the system as a whole - and vice versa. Subsequently, their actions could be a disadvantage to themselves.

Accentuating the difficulty, people then attempt to reassemble the fragments resulting from breaking wholes into parts in the belief that it is within our power to recreate the whole. Senge (1994) appeals to systemic sense on these reassembling fragments of a mirror with which, of course, a true reflection can never again be seen. He notes that we murder wholes by dissecting them into parts, yet expect to put the parts back together to recreate the original living whole.

Within the healthcare environment solutions for problems are often sought by introducing an intervention in a specific area within the supply chain or at a given time period. For instance, pre-authorisation is introduced as a prerequisite before a certain clinical procedure can be performed by a specific provider of care. The aim is to curb the costs of this specific procedure. The result, however, might be that the provider uses an alternative treatment with a higher cost, or it may result in more downstream costs as a result of treatments by either himself or another service provider, e.g. a hospital. Alternatively the same intervention might have a negative effect on the other outcomes of the system, namely accessibility, efficiency or quality of care.

According to the theory of systems dynamics, the multitude of variables existing in complex systems becomes causally related in feedback loops that themselves interact. The systemic interrelationships between feedback loops constitute the structure of the system, and it is these structures that are the prime determinant of system behaviour (Jackson, 2003:66-67).

Within the private healthcare delivery system there is no 'big brother' element co-ordinating the delivery of services.
Because of the wide range of choices a patient has, the environment within which service delivery takes place, and legal requirements that shape the playing field for providers, schemes and administrators, the structure of the private healthcare delivery system as a whole has not yet been comprehensively researched.

These arguments led to the analysis of the healthcare environment as a complex system and the notion that managed care should use a systems approach and systems principles. Thus, one can understand the structure of the complex healthcare system in order to intervene in such a way so as to ensure behaviour that fits in with the goals of the PHDS.

\section{The private healthcare delivery system (PHDS) from a systems perspective.}

Analysing the PHDS from a systems perspective requires a model that connects all the driving forces at play within the system. By identifying the elements and relationships as well as the interrelatedness of the different elements and driving forces, the PHDS from a system's perspective can be depicted (refer Figure 8).

The outcomes of the PHDS as mentioned can be measured in terms of the four elements discussed: cost, access, efficiency and quality.

Should the Private Healthcare Delivery System (PHDS) be analysed from a systems perspective, it is clear that the four role players are interconnected not only to each other (relationships 9-20), but also to the PHDS and have a direct influence on the outcomes of the PHDS, namely the problems of cost, access, efficiency and quality.

In order to understand the PHDS as a whole it is also important to understand what drives the different role player behaviour.

Patients behave in a certain way because of the influence other role players have on them and vice versa, as well as factors such as their financial ability (relationship 21) and their needs (relationship 23).

In the same way the other three role-players have an influence on each other, on the private healthcare delivery system, and are influenced by other variables depicted in the model.

All of these relationships indicate the different 'influence flows' that exist and create the PHDS system as a whole, as well as having an influence on its outcomes as described. 


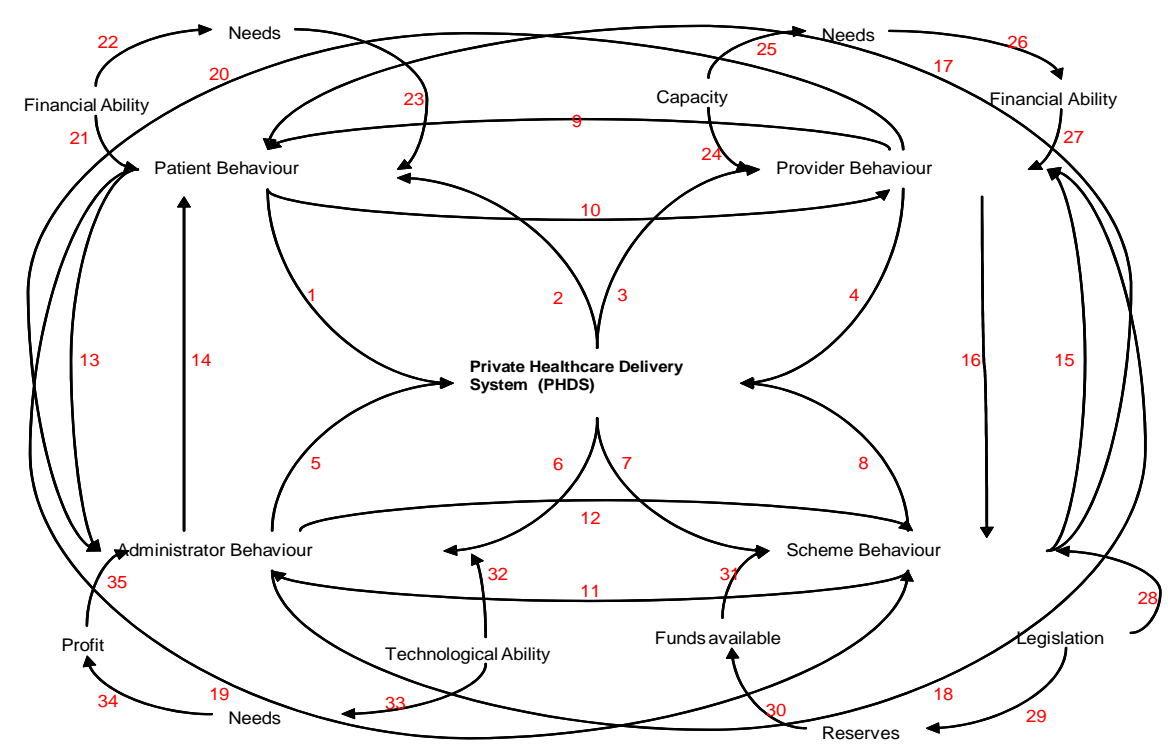

Figure 8: A system's perspective of the PHDS

\section{The PHDS within the environment}

Figure 9 illustrates how outcomes are linked to the drivers of the PHDS.

The PHDS is a result of the drivers under the left arrow in the diagram. Role player behaviour drives the system and has an influence on the system and vice versa.

Supply and demand plays a critical and self-regulating role in any economic environment. Economic systems which are traditionally unregulated do not simply expand until they reach a point of no return. The relative influence of supply of goods and the factors surrounding it versus consumer demand for goods may often, without regulatory interference, force an economic system into equilibrium (Mcquire, 2001).

When demand exceeds supply for instance, price inevitably rises, producing a reduction in demand, and an attractive business opportunity to suppliers to produce more goods. The reverse also applies. It would therefore appear that the lack of these principles in the private healthcare supply and demand system, coupled with a relatively high degree of regulatory interference, actually inhibits self-regulation within the system.

Due to a myriad of suppliers in the supply chain in the current PHDS, it is virtually impossible to coordinate the delivery of care on a pro-active basis. Most co-ordination takes place 'after the fact' by way of declining payments.

The outcomes of the system constitute a certain cost for healthcare, access to a certain percentage of the population, a certain degree of efficiency, and a certain quality of care.

\section{Conclusion}

Using systems thinking expands one's ability to get to grips with management issues and, consequently, particularises opportunities that exist for improvement (Senge 1994). This study aims to use systems thinking to construct a model that will assist managers in the healthcare environment to improve outcomes of the private healthcare delivery system.

The study will use a panel of experts (Delphi technique) from each of the different role-player groups to establish a set of principles that will define the role of managed healthcare in the PHDS and, more specifically, in the South African context. Future articles will report back on this process.
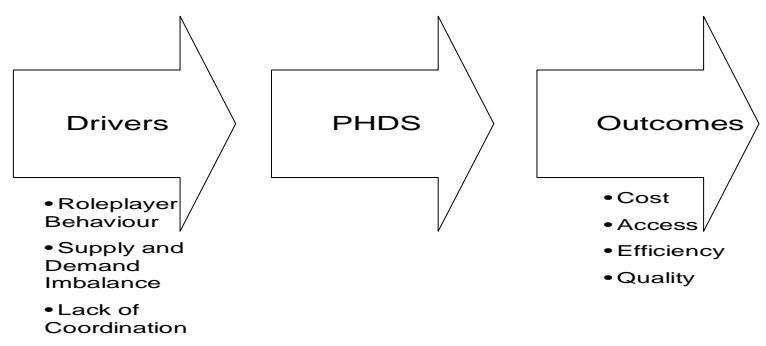

Figure 9: The PHDS - Its drivers and outcomes

\section{References}

Ackoff, R.L 1974. Redesigning the future - A systems approach to societal problems. John Wiley \& Sons, New York.

Beeld. 2003. 'Fokus op koste laat gehalte in slag bly'. 19 March. 
Business Day. 2003. 'Staying alive in SA is a costly business'. 14 January.

Council of Medical Schemes. 2003. Report of the Registrar of medical schemes - 2002/3. CMS.

Department of Finance. 2004. 'Budget highlights - Budget at a glance’. [online] URL: www finance.gov.co.za.

Dostal, E. 2004. Biomatrix. A systems approach to organisation and societal change. Stellenbosch: Sun Media.

Financial Mail. 2003. 'Taming the beast - Excellent hospital results raise medical aid members' ire'. 5 December: 71.

Gharajedaghi, J. 1999. 'Systems thinking. Managing chaos and complexity. A platform for designing business architecture.' Johannesburg: Butterworth Heinemann Pubishers.

Hartley, W. 2001. 'Private health care is "massively wasteful” ', Business Day, 14 March:5.

Hoffman, H. 2004. Personal interview.

Jackson, M.C. 2003. Systems thinking. Creative holism for managers. West Sussex, England: John Wiley \& Sons, Ltd.

Luis, J. \& Wessels, M. 2004. Changes in the provision of health care in South Africa. Bellville: University of Stellenbosch Business School.

Makgetla, N. 2003. 'Health system is new apartheid', Business Day, 25 July:9

Mcquire, T.G 2001. 'Physician agency' In Culyer, A.J. \& Newhous, J.P. (Eds.). Handbook of health economics, Vol 1 A. Amsterdam: North Holland Publishers.

Schickeling, M. 2002. Personal interview.

Senge, P. 1994. The fifth discipline. Strategies and tools for building a learning organisation. London: Nicholas Brealey Publishing.

Sunday Times, 18 June 2000.

Van Wyk, G.C.B, 1996. 'Medicine and medical process as a learning system.' A dissertation submitted in fulfillment of the requirements for the Master in Philosophy in Systems Management. University of Cape Town.

World Health Organisation. 2000. World Health Organisation, 2000. 
